better than the product normally offered, sales increased; in a fourth product, where quality was lower, sales fell. These results suggest that when locally grown quality is good, signing can increase sales, but locally grown designations will not compensate for lower quality.

\section{Implications}

Although California consumers at the two study sites believe that purchasing locally grown products supports local agriculture and provides a fresher product, they do not actively seek them. When locally grown products, identified by sign, are of high quality, sales can increase.

Large supermarkets are less able to market produce from small local farmers because the quantity produced may not be adequate, and quality, packaging, and supply may be inconsistent. Smaller supermarket chains and independents, however, can benefit from the positive aura of "locally grown." Consumers view locally grown produce as fresher, and recognize the positive impact on the local economy. Thus, supermarkets advertising locally grown produce can be viewed as both supporting the community and providing high-quality produce for customers. It is imperative, however, that the local produce be of good quality. Consumers are attracted to locally grown items, but not at the expense of quality and price. Supermarkets should not plan to charge more for locally grown items. Consumers expect them to be cheaper or the same price.

Some consumers can correctly name locally grown produce, but others cannot identify which crops are grown locally. Therefore, organizers of promotion campaigns should not assume consumers are knowledgeable about local produce and should include explicit identification.

Because relatively few customers appear to be aware that their supermarket features locally grown items, more aggressive advertising programs would be appropriate. Development and promotion of a locally grown logo could increase awareness. If items identified as locally grown are always of good quality, the perception of consumers that locally grown is fresher will grow, thereby enhancing demand for locally grown produce.

More research is needed to fully describe consumer response to locally grown items when price and quality difference are controlled.

C. M. Bruhn is Extension Specialist, Food Science and Technology, UC Davis; P. M. Vossen is Cooperative Extension Farm Advisor, Sonoma County; $E$. Chapman was formerly with the UC Small Farm Center; and S. Vaupel is an independent consultant.

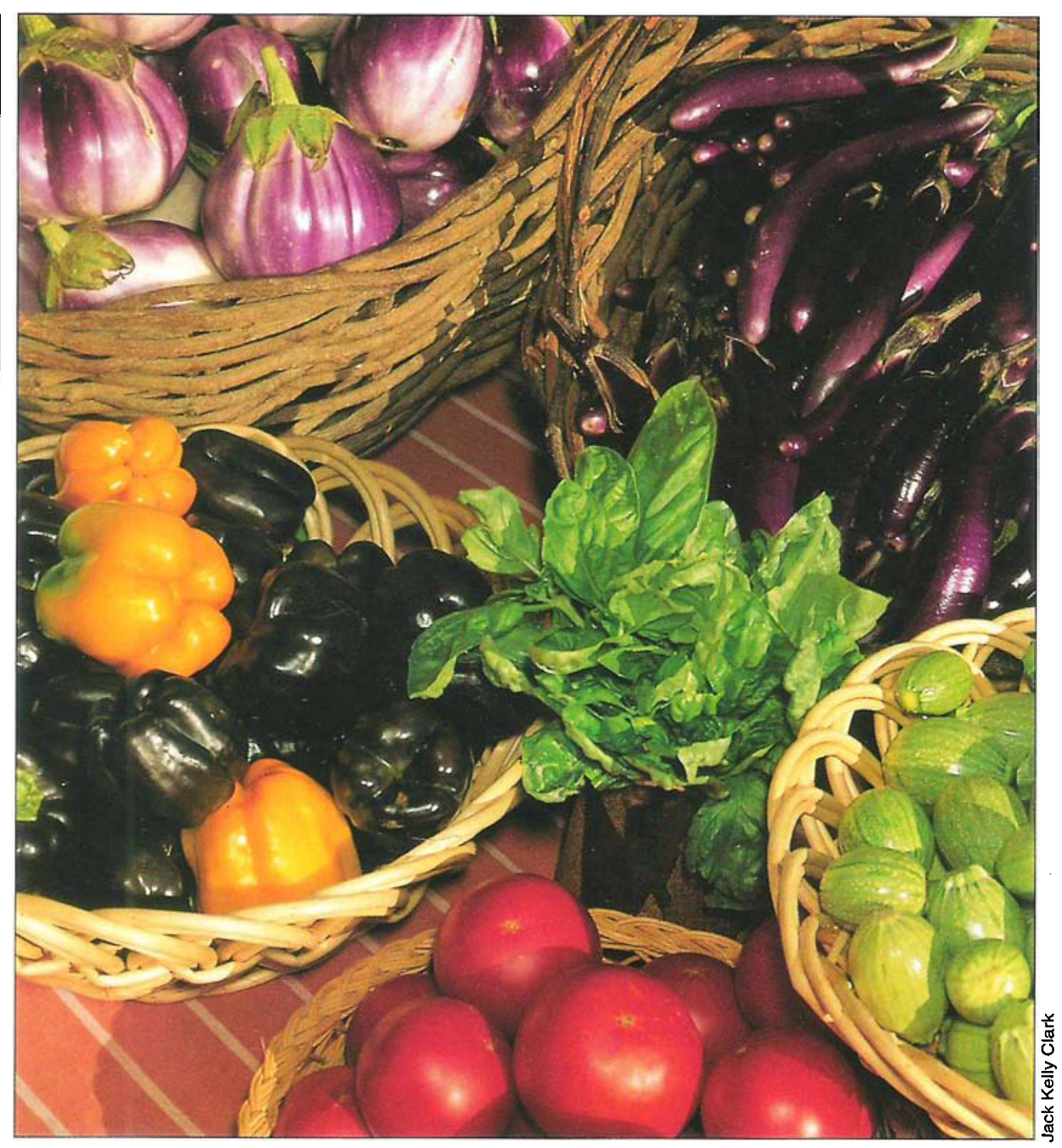

\title{
Fuji apple, radicchio, basil, walnut top specialty crop research needs
}

\author{
Stephen H. Brown $\square \quad$ Louie H. Valenzuela
}

\section{Growers and distributors list 130 specialty crops they think need re- search. Heading the list: Fuji apple, radicchio, basil, and walnut.}

Over the last two decades, many California-grown crops that were once considered exotic or "specialty" have become commonplace in supermarkets. Many of these crops have received little or no research attention. A statewide survey of growers and handlers was conducted in 1989 with these objectives: to determine specific research needs and to plan future University studies of specialty crops.

\section{The survey}

A questionnaire was sent to 500 growers and distributors (handlers) throughout California. We received 69 responses, a response rate of $14 \%$. Specialty crops were identified for the respondents as unusual varieties of common crops as well as ethnic and exotic crops.

Growers and distributors were asked to list one or more specialty fruit, vegetable, herb, and nut crops needing research attention. They were asked to identify up to five commodities in each category. For each commodity listed, growers were asked to choose from a list of possible ar- 


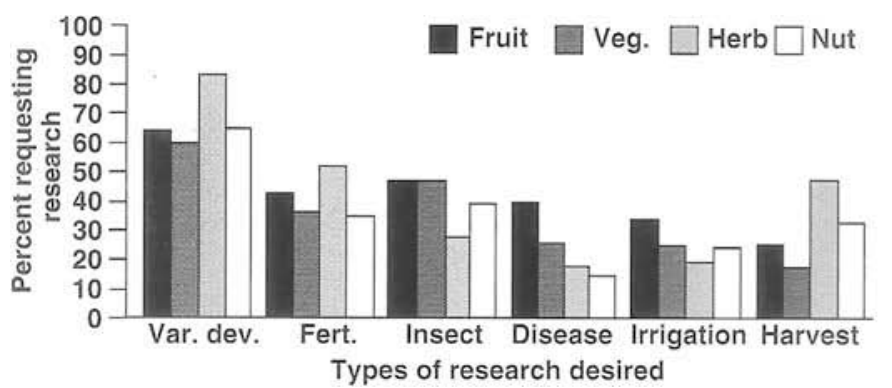

Fig. 1. Growers of specialty fruits, vegetables, herbs, and nuts indicated research in varietal development as their greatest need. Other categories covered in survey: fertilization, insect control, disease control, irrigation, and harvesting.

eas of research: varietal development, irrigation, fertilization, insect control, disease control, or harvesting. Distributors were asked to choose from among storage, packaging, and marketing as areas of desired research. Growers were also asked to identify their production methods as organic or conventional.

\section{Crop diversity}

Of the respondents, 33 grew vegetables, 38 grew fruits, 13 grew herbs, and 9 grew nuts. Many growers grew two or more categories of crops. Some growers also marketed their crops - 25 grower/marketers were identified.

Respondents identified 130 commodities as needing research attention. Table 1 lists them under four categories: fruits, vegetables, herbs, and nuts. Specialty vegetables (48 commodities) head the list as having the most needs for research; 38 fruits and 27 herbs also require research attention. Nuts (17 crops) are less frequently mentioned as needing study. Identification of the 130 specialty commodities attests to their growing appeal among farmers, marketers, and consumers.

A little more than $10 \%$ of the respondents indicated no desire for research on any crop. Of the growers and handlers responding, $18.9 \%$ identified only one commodity as needing research attention, $17.4 \%$ desired research on as many as 6 out of 10 commodities, and $5.8 \%$ listed from 16 to 20 crops requiring research.

\section{Crops most identified}

Fuji apple was listed by all respondents as the number-one specialty fruit requiring research study. Radicchio was the vegetable most frequently cited as needing research attention. Among herbs and nuts, basil and walnut were listed as the leading crops requiring study. All four specialty crops are commonly found today in California supermarkets. The survey indicates that university research may be lagging behind the production and marketing of these specialties. Table 2 lists the five crops

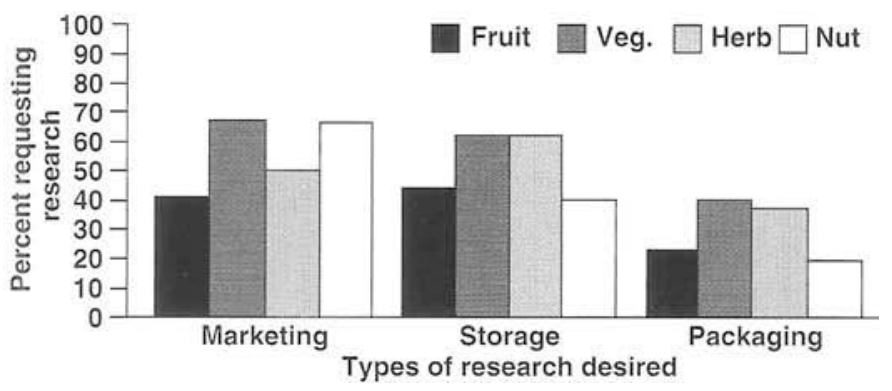

Fig. 2. Marketing of vegetables and nuts was the strongest research interest among specialty crop distributors surveyed.

\begin{tabular}{|c|c|c|c|}
\hline Fruits & Vegetables & Herbs & Nuts \\
\hline Apples: Fuji, heirlooms & Amaranth & Anise & Almond \\
\hline Apricot & Artichoke: baby & Arugula & Butternut \\
\hline Avocado & Beans: green, snap & Basil & Cashew \\
\hline \multirow{3}{*}{$\begin{array}{l}\text { Berries: raspberry, } \\
\text { boysenberry, } \\
\text { blueberry }\end{array}$} & Beets: baby & Chamomile & Chestnut \\
\hline & Bok choy & Chervil & Coconut \\
\hline & Broccoli & Chicory & Dates \\
\hline Carambola & Brussels sprouts & Chili & Hazelnut \\
\hline Cherimoya & Cabbage & Chive & Heartnuts \\
\hline Cherry & Cabbage: Chinese & Chrysanthemum & Macadamia \\
\hline Currants: black, red & Cactus & Cilantro & Palmnut \\
\hline Feijoa & Cauliflower & Dill & Peanut \\
\hline Fig & Celery & Fennel & Pecan \\
\hline Gooseberry: cape & Collard & Garlic: elephant & Pine nut \\
\hline Grapes & Corn: blue, sweet & Ginger & Pistachio \\
\hline \multirow{2}{*}{$\begin{array}{l}\text { Guava: strawberry, } \\
\text { lemon }\end{array}$} & Cucumber: pickling & Lavender & Pumpkinseed \\
\hline & Eggplant & Lemongrass & Sunflowerseed \\
\hline Jujube & Endive & Mint & Walnut \\
\hline Kiwi & Garlic & Oregano & \\
\hline Kumquat & Greens: Asian & Parsley & \\
\hline Lime & Haricot vert & Rosemary & \\
\hline Lychee & Kiwano (horn melon) & Saffron & \\
\hline Mango & Lettuce: baby, French & Savory & \\
\hline Melons & Lima beans & Shallot & \\
\hline Minutina & Mushrooms & Tamarind & \\
\hline Nectarine & Mustard & Tarragon & \\
\hline Orange: blood & Okra & Thyme & \\
\hline Papaya & Onion: green, red & Watercress & \\
\hline Passionfruit & Pea: blackeye, English, & & \\
\hline Peach & purple, snow, sugar-snap & & \\
\hline Pear & Peppers: bell, Italian, color & & \\
\hline Pear: Asian & Potato & & \\
\hline Persimmons & Radicchio & & \\
\hline Pineapple & Radish: daikon & & $\therefore$ \\
\hline Plantain & Rappini & & \\
\hline Plums & Rhubarb & & \\
\hline Sapote & Rice: wild & & \\
\hline Strawberry & Root: taro, namé, malanga & & \\
\hline Tangerine & Salsify: black & & \\
\hline Tamarillo & Spinach & & \\
\hline Tomatillo & Sprouts & & \\
\hline \multirow[t]{5}{*}{ Tomato: hothouse } & Squash: baby summer, winter & & \\
\hline & Turnips & & \\
\hline & Verdolaga (purslane) & & \\
\hline & Yucca & & \\
\hline & Zucchini: baby, flowers & & \\
\hline
\end{tabular}

TABLE 2. Specialty crops most frequently selected as needing research attention, by crop category

\begin{tabular}{|c|c|c|c|}
\hline Fruits & Vegetables & Herbs & Nuts \\
\hline $\begin{array}{l}\text { Apple: Fuji } \\
\text { Grapes } \\
\text { Persimmon } \\
\text { *Guava: strawberry } \\
\text { *Pear: Asian } \\
\text { "Tomato: hothouse }\end{array}$ & $\begin{array}{l}\text { Radicchio } \\
\text { "Peppers: bell, Italian } \\
\text { *Lettuce: baby, French } \\
\text { †Greens: Asian } \\
\text { †Onion: red } \\
\text { †Squash: winter }\end{array}$ & $\begin{array}{l}\text { Basil } \\
\text { Garlic: elephant } \\
\text { Chive } \\
\text { Cilantro } \\
\text { Dill }\end{array}$ & $\begin{array}{l}\text { Walnut } \\
{ }^{*} \text { Almond } \\
\text { "Chestnut } \\
\text { *Pine nut } \\
\text { †Macadamia } \\
\text { †Peanut } \\
\text { †Pistachio }\end{array}$ \\
\hline
\end{tabular}




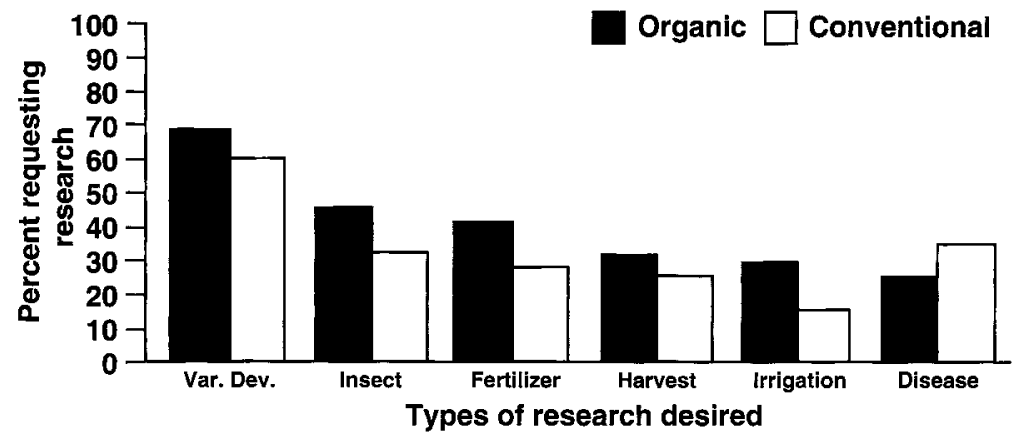

Fig. 3. Varietal development was the most pressing research need expressed by both organic and conventional growers of specialty crops.

most frequently selected by respondents as needing study, arranged by crop category.

\section{Growers' research needs}

Growers of fruits, vegetables, herbs, and nuts were asked to choose from among six possible areas of research for each commodity listed: varietal development, irrigation, fertilization, insect control, disease control, and harvesting. A respondent could choose multiple areas of research for a single commodity. Growers from all crop categories showed strong preference for research on varietal development. Varietal development was requested by $60 \%$ of the vegetable producers and by $84 \%$ of the herb growers (fig. 1). No other area of research request ranked so high.

All grower groups strongly desired studies on fertilizer application. Over half of all herb growers (52\%) wanted such studies. Fertilization was least frequently noted by nut growers, although even there more than one-third were interested in such work (35\%).

Growers in all crop categories strongly supported insect management studies. Specialty fruit and vegetable growers most frequently requested university attention in that area ( $47 \%$ for each category). Among nut and herb growers, 40 and $32 \%$ made similar requests.

Overall, hẹrb growers came out the most strongly for research on harvesting (48\%); only $18 \%$ of vegetable growers requested attention in that area. Grower concerns for irrigation or water management practices were not strongly reflected in this survey. Among the four grower groups, between 25 and $35 \%$ expressed the need for university research in water application. These figures are well below those for other areas of research interest. In light of California's drought, one might have expected to see more requests for irrigation studies had the survey been conducted in 1992.

Overall areas of research requests varied greatly among the four crop categories. For example, nut growers considered dis- ease control to be the area of least concern $(15 \%)$, whereas $40 \%$ of fruit growers wanted study in that area. In three of six research areas, herb growers were the most concerned about production (varietal development, fertilization, and harvesting), a possible reflection of the relative novelty of this crop category in the U.S. market.

\section{Distributors' research needs}

Distributors were asked about possible research assistance in marketing, storage, and packaging. Marketing of specialty crops was the primary concern (fig. 2). Vegetable and nut distributors expressed the strongest desire for help in marketing their products (68 and 67\%, respectively) Of the respondents desiring help in marketing specialty commodities, many were both growers and distributors. This may indicate increased opportunities for Farm Advisors to become involved in both the production and marketing of certain commodities.

Equal proportions of herb and vegetable distributors requested UC assistance for research on storage $(62 \%)$. Specialty fruit and nut growers also asked for studies on storage from UC researchers (43 and $40 \%$, respectively). The greater rate of requests for storage assistance among specialty herb and vegetable distributors is not surprising, as both commodities are subject to rapid decline in quality immediately after harvest.

Finally, of the three research areas queried, distributors showed the least interest in packaging (fig. 2). As with storage, however, concern for packaging of specialty herbs and vegetables ranked higher than for specialty fruits and nuts $(38,41$ 24 , and $20 \%$, respectively) (fig. 2). Herbs and vegetables usually are more perishable, so their distributors are more concerned with extending shelf lives.

\section{Organic versus conventional}

Growers were asked to identify themselves as organic or conventional producers. Thirty-three of the respondents (48\%) identified themselves as organic growers. Organic growers requested greater research priority for insect control, fertilization, irrigation, and varietal development (fig. 3). For conventional and organic growers alike, varietal development was the first priority for research.

Almost twice as any organic growers as conventional growers requested improvements in farm irrigation. Only $16 \%$ of the conventional growers listed irrigation as a priority for research. When compared to conventional growers, organic growers expressed a greater need for research attention in all production areas queried except disease control.

\section{Conclusions}

Growers and distributors listed a total of 130 California specialty crops as deserving research. In general, across all crop categories, growers indicated a consistent need for varietal development of their commodities. Growers also expressed their need for fertilizer trials and insect management techniques.

Distributors of all crop types expressed interest in marketing assistance. Vegetable and herb distributors were most concerned with shelf lives of their perishable commodities, and expressed their desire for UC assistance in improving storage and packaging methods.

Organic growers requested help in all areas of production, except disease management, more frequently than did conventional growers. Compared with conventional growers, organic growers were more likely to request assistance in varietal development, insect control, fertilization, irrigation, and harvesting.

Farm Advisors and Extension Specialists doing field work may want to organize their research in accordance with our findings, and concentrate their work in this order of importance: varietal development and testing, insect management, fertilizer trials, harvesting, and disease control.

University and private industry personnel working with specialty growers and distributors need to be acutely aware of their marketing needs. Recommendations on growing specialty commodities should be based on ease of production as well as on market demand for the particular crop.

S. H. Brown is UC Cooperative Extension Consumer Marketing Advisor, Los Angeles County, and L. H. Valenzuela is Cooperative Extension Farm Advisor, Santa Barbara and San Luis Obispo counties.

The authors greatly appreciate the assistance provided by Carol Adams, Statistician, UC Riverside. 